\title{
Optimal phasing of the European tidal stream resource using the greedy algorithm with penalty function
}

Neill, S.P.; Lewis, M.J.; Hashemi, M.R.

\section{Energy}

DOI:

10.1016/j.energy.2014.07.002

Published: 22/07/2014

Publisher's PDF, also known as Version of record

Cyswllt i'r cyhoeddiad / Link to publication

Dyfyniad o'r fersiwn a gyhoeddwyd / Citation for published version (APA):

Neill, S. P., Lewis, M. J., \& Hashemi, M. R. (2014). Optimal phasing of the European tidal stream resource using the greedy algorithm with penalty function. Energy, 73, 997-1006.

https://doi.org/10.1016/j.energy.2014.07.002

\footnotetext{
Hawliau Cyffredinol / General rights

Copyright and moral rights for the publications made accessible in the public portal are retained by the authors and/or other copyright owners and it is a condition of accessing publications that users recognise and abide by the legal requirements associated with these rights.

- Users may download and print one copy of any publication from the public portal for the purpose of private study or research.

- You may not further distribute the material or use it for any profit-making activity or commercial gain

- You may freely distribute the URL identifying the publication in the public portal ?
}

Take down policy

If you believe that this document breaches copyright please contact us providing details, and we will remove access to the work immediately and investigate your claim. 


\title{
Optimal phasing of the European tidal stream resource using the greedy algorithm with penalty function
}

\author{
Simon P. Neill", M. Reza Hashemi, Matt J. Lewis \\ School of Ocean Sciences, Bangor University, Menai Bridge, LL59 5AB, UK
}

\section{A R T I C L E I N F O}

\section{Article history:}

Received 24 May 2014

Received in revised form

30 June 2014

Accepted 1 July 2014

Available online 22 July 2014

\section{Keywords:}

Tidal stream arrays

Tidal energy

Tidal phasing

Greedy algorithm

Optimisation

NW European shelf seas

\begin{abstract}
A B S T R A C T
The regular periodicity of astronomical tides allows their accurate prediction, and so it should be possible to determine how best to optimise the future distribution of arrays of tidal energy devices for any shelf sea region. By considering together the magnitude and phase of tidal currents over a shelf sea region, maximum aggregated power generation, with minimal periods of low generation, can be deduced. Here, we make use of the greedy algorithm to optimise future exploitation of the tidal stream resource over the northwest European shelf seas, a region which contains a world-leading tidal energy resource. We also apply a penalty function to the greedy algorithm, favouring the selection of future hypothetical sites where power generation would be out-of-phase with previously developed sites. Our results demonstrate that the Pentland Firth and Channel Islands would be optimal sites for parallel development for relatively low numbers of arrays, with important contributions from the Irish Sea for larger scale exploitation. Although there is minimal phase diversity between European tidal stream sites to deliver firm power generation, it is possible that the vertical tide could contribute to such baseload through the parallel development of lagoons or impoundments.

๑) 2014 The Authors. Published by Elsevier Ltd. This is an open access article under the CC BY license
\end{abstract} (http://creativecommons.org/licenses/by/3.0/).

\section{Introduction}

In contrast to the stochastic nature of waves [1], the regular periodicity of tides allows their prediction far into the future [2], and this presents us with the opportunity to accurately quantify the role of tidal energy in the future energy mix. Most tidal energy is produced during periods of spring tides, and particularly at times of peak flood or ebb tidal currents. Although we cannot address the longer timescale variability problem of the spring/neap cycle, we could optimise exploitation of the tidal stream resource by maximising the opportunities offered by prioritising sites which are complementary in phase to one another over a semi-diurnal timescale. In this way, tidal energy, particularly tidal streams, could have a contribution towards supplying baseload to the electricity network [3]. Tidal streams can be exploited by a range of technologies that include horizontal axis turbines [4], vertical axis turbines [5], and hydrofoils [6].

Iyer et al. [7] demonstrated through an examination of the Atlas of UK Marine Renewable Energy Resources that there is insufficient diversity between UK tidal stream sites to deliver firm power

\footnotetext{
* Corresponding author.

E-mail address: s.p.neill@bangor.ac.uk (S.P. Neill).
}

generation. However, the conclusions of this study were based on a limited number of sites, since first generation tidal stream technology was assumed, which requires mean spring peak current speeds of $2.5 \mathrm{~m} / \mathrm{s}$, and water depths in the range $25-50 \mathrm{~m}$. Further, the Atlas of UK Marine Renewable Energy Resources does not span international boundaries, and so the results are UK-centric. In the present study, we re-visit the problem of tidal phasing with fewer constraints on the resource, and by considering the entire NW European shelf seas, looking towards future energy security in terms of (a) future generations of tidal energy devices (which are likely to operate in deeper waters and be associated with lower cutin and rated velocities), and (b) the possibility of a European supergrid, which would enable geographically discrete regions to aggregate their electricity generation into a unified electricity network via subsea and overland cables [8,9]. Further, we make use of an optimisation technique that has been successfully applied to a wide range of research topics, the greedy algorithm, [e.g. Ref. [10]], to optimise the aggregation of power from diverse tidal stream sites by maximising net power generation, while minimising periods when instantaneous power generation is below a threshold, by applying a penalty function.

After a description of the hydrography of the northwest European shelf seas, with particular emphasis on the tides (Section 2), we describe the three-dimensional (3D) oceanographic model of 
the region used to apply the greedy algorithm with a penalty function (Section 3). We consider a range of future tidal stream extraction scenarios, from first-generation arrays that will likely be developed over the next decade, through to extreme scenarios of many thousands of devices distributed over a number of locations throughout the NW European shelf seas (Section 4).

\section{The northwest European shelf seas}

The NW European shelf seas provide Europe with a world leading resource for the development of a marine renewable energy industry, and are therefore host to a large number of commercial projects and test centres, such as the EMEC (European Marine Energy Centre) wave and tidal test centre in Orkney, and the Marine Current Turbines/Siemens tidal array project in Anglesey (Irish Sea). Although the wave resource is substantial, [e.g. Ref. [1]], and there is scope for exploiting the potential energy contained in the vertical tide, [e.g. Ref. [11]], the focus of the present work is on the horizontal tide, i.e. tidal streams.

The NW European shelf seas, located on the northeastern margin of the North Atlantic, are generally shallower than $200 \mathrm{~m}$ (Fig. 1). The Celtic Sea, Malin Sea and northern North Sea are exposed to Atlantic waters, with water depths in the range 100-200 m, with the exception of the deeper $(600 \mathrm{~m})$ Norwegian Trench in the northeastern North Sea. The Celtic Sea borders the Irish Sea to the north, a semi-enclosed water body containing a north-south orientated channel of depth $250 \mathrm{~m}$. To the east of the Celtic Sea, the English Channel connects to the southern North Sea.

There are regions of the NW European shelf seas which contain some of the largest tidal ranges in the world, e.g. the Bristol Channel and the Gulf of St. Malo. There are three M2 (principal lunar semidiurnal constituent) amphidromic points of near-zero tidal range in the North Sea, a further one in the North Channel of the Irish Sea, and two degenerate amphidromic points: one in the English Channel, and the other in St. George's Channel [12] (Fig. 2a). Tidal currents are generally high in the Irish Sea and English Channel, and moderately high in the Celtic Sea and in the southern and western North Sea $[13,14]$. Since friction gradually removes energy from the tides at the bottom of the water column, the total attenuation in large seas, e.g. the North Sea, is pronounced [15,16]. In the North Sea, the propagation of the tidal wave is cyclonic. The tidal wave enters the North Sea by travelling southward along the east coast of Scotland, where the tidal currents and elevations are much greater than near Denmark and Norway, at the end of the tide's transit.

Regions of high tidal currents throughout the NW European shelf seas are concentrated in areas where there is a bathymetric enhancement or topographic restriction (Fig. 2b), e.g. through straits such as the Pentland Firth [17] and the Alderney Race [18], or past headlands such as Portland Bill in the English Channel [19] and the Skerries to the northwest of Anglesey [20]. However, the sea space at such competitive high energy sites is limited, and it is likely

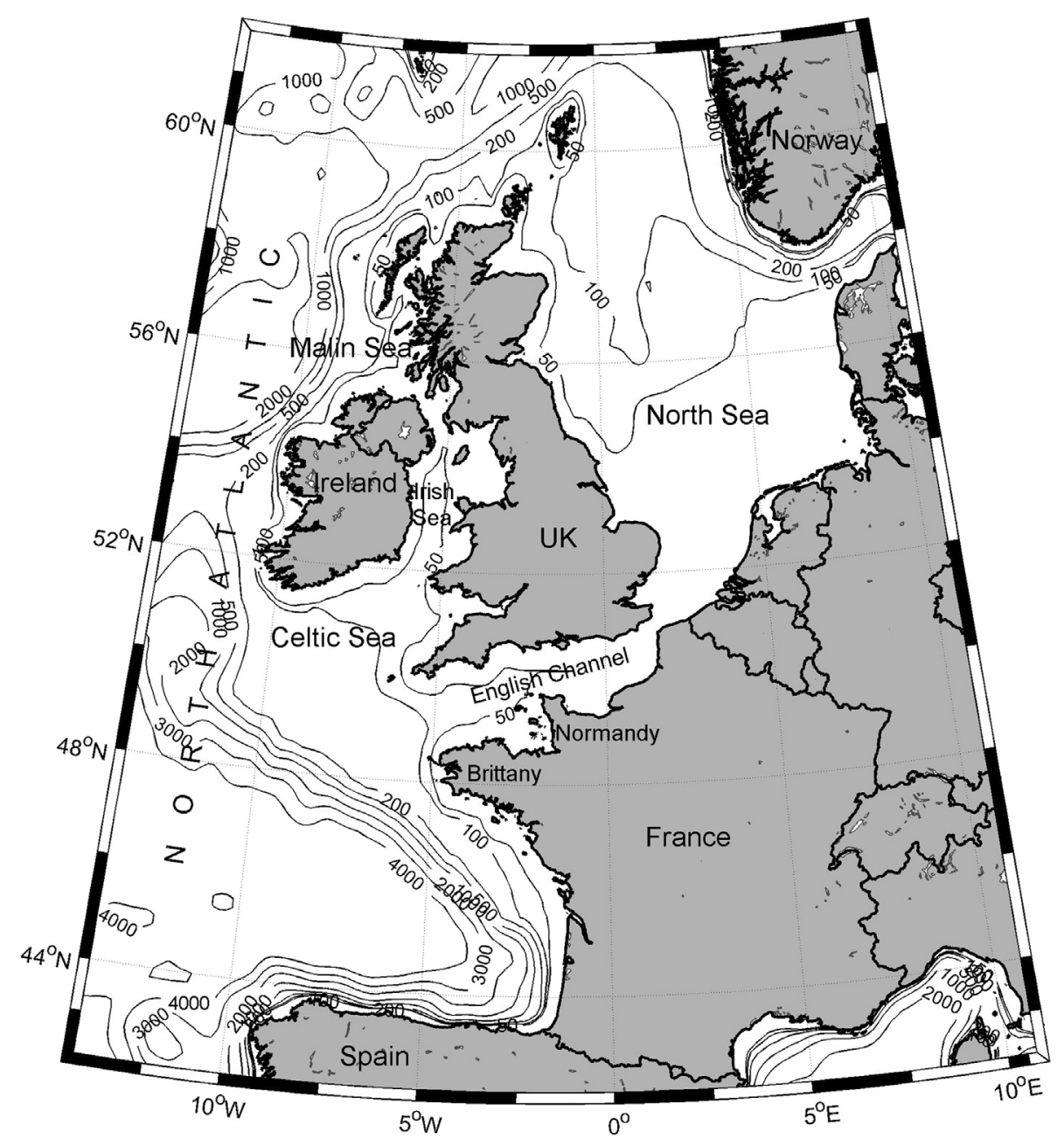

Fig. 1. The northwest European shelf seas. Contours are bathymetry in metres. 
(a) M2 co-tidal chart

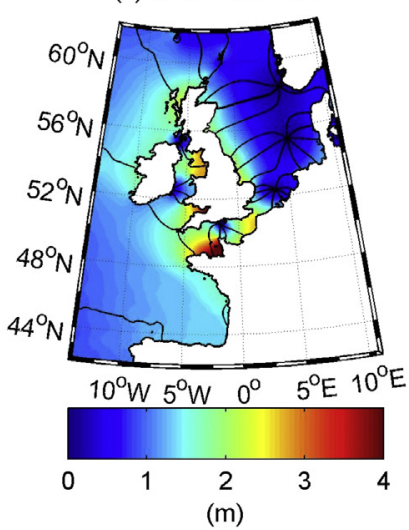

(b) M2 current amplitude

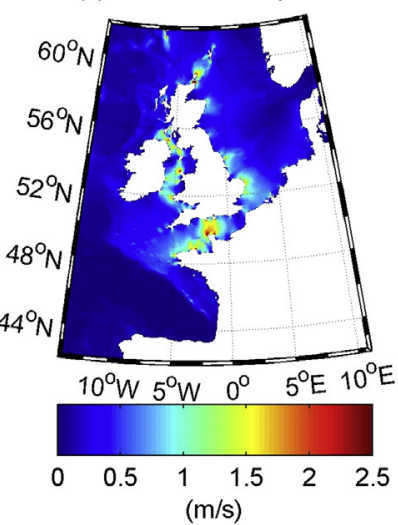

(c) M2 current phase

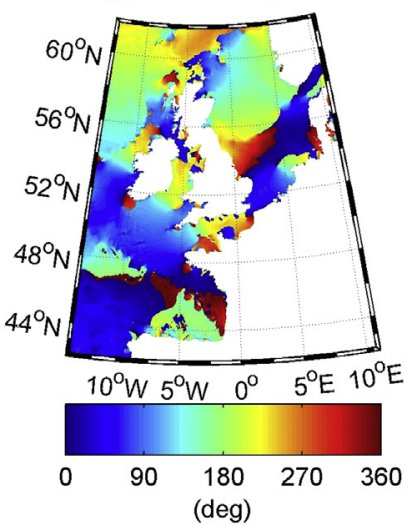

Fig. 2. (a) Co-tidal chart of M2 elevation, and (b) amplitude and (c) phase of the M2 tidal currents over the NW European shelf seas.

that concentrated exploitation of such sites could lead to feedbacks between energy extraction and the resource [18]. Therefore, in the present study, we additionally investigate the optimisation of lower tidal stream sites in circumstances where the phase of such sites is complementary to the phase of previously developed sites (Section 3.2).

\section{Methods}

\subsection{ROMS model}

ROMS (Regional Ocean Modelling System) is an advanced opensource 3D model under active development by a large and diverse research community, led by Rutgers University and the University of California, Los Angeles [21]. ROMS is a free-surface hydrostatic ocean circulation model based on finite-difference approximations of the Reynolds-averaged Navier-Stokes equations. It uses stretched, terrain-following (sigma) coordinates in the vertical, and orthogonal curvilinear coordinates in the horizontal. A wide variety of turbulence submodels, advection schemes, and boundary conditions are available in ROMS. ROMS can also be readily coupled to atmospheric and wave models, and includes sediment dynamics and morphodynamics [22]. ROMS has been used to examine a range of oceanographic processes at a wide range of scales from ocean basin [23] to archipelagos [24].

The study area extended from $14^{\circ} \mathrm{W}$ to $11^{\circ} \mathrm{E}$, and from $42^{\circ} \mathrm{N}$ to $62^{\circ} \mathrm{N}$ (Fig. 1). The ROMS model domain was discretised with a horizontal curvilinear grid, with a longitudinal resolution of $1 / 24^{\circ}$ and variable latitudinal mesh size $\left(1 / 32^{\circ} \sim 1 / 51^{\circ}\right)$ to ensure an approximately uniform cell aspect ratio. The model bathymetry was based on the ETOPO (Earth Topography Digital Dataset) (www.ngdc.noaa.gov/mgg/global) global bathymetric dataset, which is available at a resolution of $1 / 60^{\circ}$. The vertical model grid consisted of 11 layers distributed according to the ROMS topographic-following coordinate system. The open boundaries of the tidal model were forced by elevation (Chapman boundary condition) and tidal velocities (Flather boundary condition), generated using 10 tidal constituents obtained from TPXO7 (TOPEX/Poseidon) global tide data which has $1 / 4^{\circ} \times 1 /$ $4^{\circ}$ resolution (volkov.oce.orst.edu/tides/). These comprised the principal lunar (M2) and solar (S2) semi-diurnal constituents, the larger lunar elliptic (N2) and lunisolar (K2) semi-diurnal constituents, the lunar (O1), solar (P1), lunisolar (K1) and larger lunar elliptic (Q1) diurnal constituents, and the lunar fortnightly (Mf) and monthly $(\mathrm{Mm})$ constituents. This model of the northwest European shelf seas has been extensively and successfully validated, and full details are provided in Ref. [25].

\subsection{The greedy algorithm}

A greedy algorithm is a very simple and efficient method for solving optimisation problems. At each step, the greedy algorithm seeks the local optimum, without regard for future consequences, in an attempt to achieve the global optimum. As an example, consider a case where we have nine jobs to schedule on a supercomputer, with estimated run times of $3,5,6,10,11,14,15,18$, and $20 \mathrm{~h}$. We have three processors on which we can run these jobs, and the nature of the greedy algorithm is such that it will attempt to run the longest-running jobs first, on whatever processor is available (Fig. 3). The time to completion is $18+11+6=35 \mathrm{~h}$ for this case. The greedy algorithm is a short-sighted optimisation solution, and may not always find the global optimum, but its general success and simplicity makes it very attractive for a wide range of applications such as financial markets [26], and the layout of wind arrays [10].

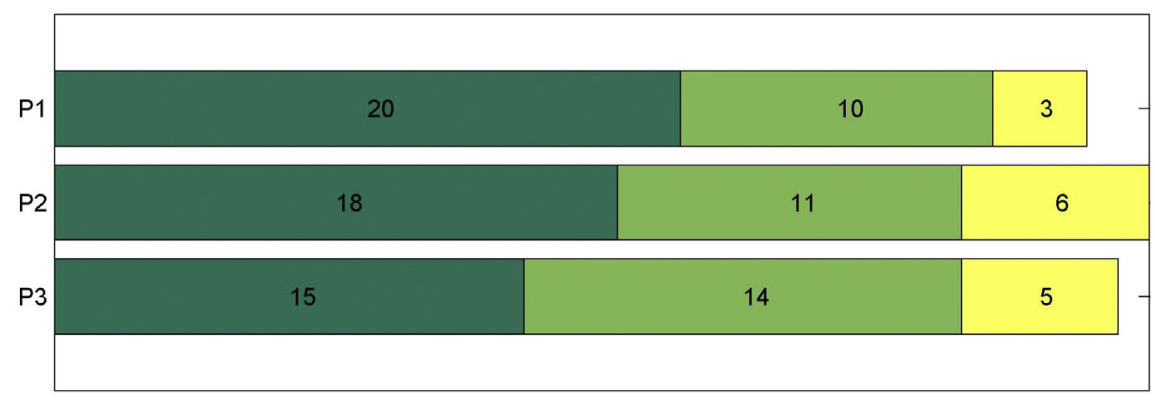

Fig. 3. Example scheduling problem solved by the greedy algorithm, with 9 jobs to schedule on 3 processors (P1, P2 and P3). 
To apply the greedy algorithm to our case study, we first need to consider the average theoretical tidal power per unit area, over a tidal cycle, which is given by

$\bar{P}=\frac{1}{T} \int_{0}^{T} \frac{1}{2} \rho u^{3} \mathrm{~d} t$

where $T$ is the period of tide, $u$ is the current velocity, and $\rho$ is the density of sea water. It is worth mentioning that the practical tidal power $\left(P_{a}\right)$ is proportional to the theoretical power, the efficiency of a tidal device $\left(C_{p}\right)$, and its rotor area (i.e. $P_{a}=C_{p} P A$ ). Due to the harmonic nature of tides, tidal current velocity can be represented as a summation of tidal components, where semi-diurnal lunar (M2) and solar (S2) constituents with periods of $12.42 \mathrm{~h}$ and $12.00 \mathrm{~h}$, respectively, are the two principal components in our region of interest. Considering the most important component, M2, the current velocity at site $i$ will be $u_{i}=H_{i} \cos \left(\sigma_{M 2} t-g_{i}\right)$, where $H$ and $g$ are the amplitude and phase, respectively, of the M2 component, and $\sigma_{M 2}=2 \pi / T_{M_{2}}$ is the angular frequency. Referring to Eq. (1), by replacing tidal velocities with harmonic functions, the mean cumulative power generated over a tidal cycle by all previously developed sites during each step of the algorithm is

$$
\begin{aligned}
\bar{P}_{\text {cum }} & =\frac{\rho}{2 T_{M_{2}}} \sum_{i=1}^{n}\left[\int_{0}^{T_{M_{2}}} u_{i}^{3} \mathrm{~d} t\right] \\
& =\frac{\rho}{2 T_{M_{2}}} \sum_{i=1}^{n}\left[H_{i}^{3} \int_{0}^{T_{M_{2}}}\left(\cos \left(\frac{2 \pi}{T_{M_{2}}} t-g_{i}\right)\right)^{3} \mathrm{~d} t\right]
\end{aligned}
$$

where $n$ is the number of arrays placed, and $H_{i}$ and $g_{i}$ are the amplitude and phase, respectively, of the M2 tidal currents at site $i$. If the objective function was to maximise the total tidal energy over a tidal cycle, the greedy algorithm would seek to maximise $\bar{P}_{\text {cum }}$, which is an indicator of the theoretical total energy generated by all sites. However, in addition to the magnitude of energy, its distribution over time is another important criterion. To account for this factor, the concept of a penalty function was implemented. In addition to the cumulative power, the period during which the tidal power is less than a threshold value is computed at each step of the algorithm. The objective function is then penalised by this period of low energy production. The selection of the threshold power, which determines the length of this period, will depend on complex economical factors, but can be simply chosen as a percentage of average power in the first instance (i.e. $P_{t}=\lambda \bar{P}_{\text {cum }}$ where $0<\lambda<1$; see Fig. 4). For very small values of $\lambda$, the function is not constrained, whereas as $\lambda$ approaches 1 the function will be highly constrained to this criterion. Consequently, the optimisation problem, which takes into account the distribution as well as magnitude of tidal energy, can be formulated as

maximise $f=\bar{P}_{\text {cum }}\left[T_{M_{2}}-T_{p}(\lambda)\right]$

where $T_{p}$ is the period during which the power is less than $P_{t}=\lambda \bar{P}_{\text {cum }}$.

The solution proceeds at each step by testing each available option, and selecting the option which maximises mean aggregated power, while minimising periods of low power generation.

A simple idealised case can be used to demonstrate how the greedy algorithm with penalty function selects the optimal sites. Considering four sites with peak current amplitudes and phases of $(3.2 \mathrm{~m} / \mathrm{s}, 0),(2.5 \mathrm{~m} / \mathrm{s}, \pi / 3),(2.2 \mathrm{~m} / \mathrm{s}, \pi / 2)$ and $(3.0 \mathrm{~m} / \mathrm{s}, \pi)$ (Fig. $5 \mathrm{a}$ ),

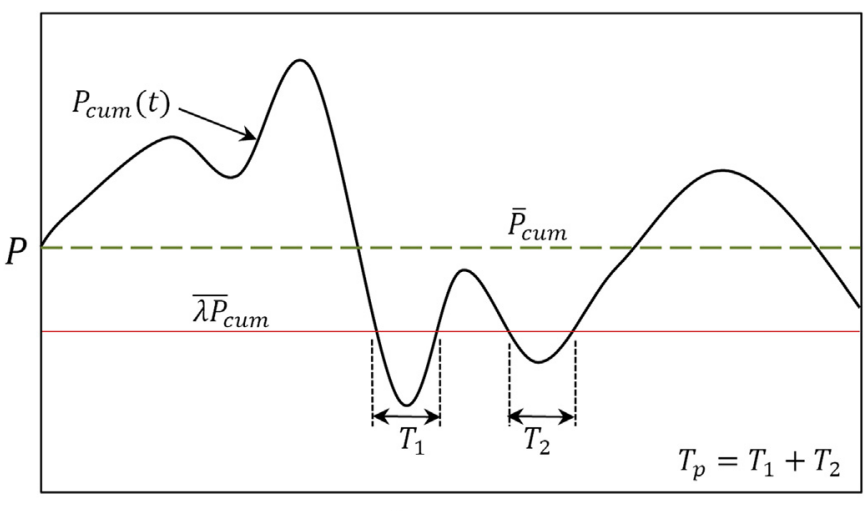

$t$

Fig. 4. Schematic of power distribution and the concept of the minimum power threshold value used to implement the penalty function.

the objective is to select two sites based on the method described above. As Fig. 5a shows, site $(3.2 \mathrm{~m} / \mathrm{s}, 0)$ has the maximum power, and this power is in phase with site $(3.0 \mathrm{~m} / \mathrm{s}, \pi)$ - the site with the second largest power $(|\sin (x)|=|\sin (x+\pi)|)$. Therefore, the algorithm firstly selects $(3.2 \mathrm{~m} / \mathrm{s}, 0)$, and if there is no distributional constraint, would logically choose $(3.0 \mathrm{~m} / \mathrm{s}, \pi)$ as the second site to maximise power. The red (in web version) line in Fig. 5b shows the distribution of the power generated by combining these two sites. In contrast, the combination of $(3.2 \mathrm{~m} / \mathrm{s}, 0)$ and $(2.2 \mathrm{~m} / \mathrm{s}, \pi / 2)$, which produces the minimum energy, leads to the best distribution. By selecting an appropriate value of $\lambda$, one can weight the distribution of the power versus the magnitude of power, or vice versa. Referring to Fig. $5 c, \lambda=0$ is equivalent to no constraint, and recommends $(3.2 \mathrm{~m} / \mathrm{s}, 0)+(3.0 \mathrm{~m} / \mathrm{s}, \pi)$, i.e. the maximum power, as the optimum solution. For values of $\lambda \geq 0.4$, the power distribution becomes the main criterion for the optimisation, and $(3.2 \mathrm{~m} / \mathrm{s}$, $0)+(2.2 \mathrm{~m} / \mathrm{s}, \pi / 2)$ is the optimum, despite a $30 \%$ reduction in the amount of energy compared with the previous scenario. In the case of choosing an intermediate value of $\lambda$ such as 0.2 , both criteria have similar weights in the optimisation process.

\subsection{Model implementation}

Since the phase relationship between the principal tidal constituents, particularly the semi-diurnal constituents, will be approximately constant at each site, we make use of only the principal semi-diurnal lunar constituent (M2) in our analysis and application of the greedy algorithm. The amplitude and phase of the M2 tidal currents calculated from tidal analysis of the ROMS model output are shown in Fig. 2b,c. Current amplitudes vary by an order of magnitude over the NW European shelf seas, but various high commodity regions of strong tidal flow stand out in Fig. 2b, such as the Pentland Firth, Anglesey Skerries, and the Alderney Race. In the phase plot (Fig. 2c), we can see that many of the key tidal energy sites are approximately in-phase or $180^{\circ}$ outof-phase $^{1}$; for example, the high tidal stream sites at the Anglesey Skerries and Alderney Race are within $20-30^{\circ}$ (40-60 min) of each other, and the Pentland Firth is around $130-160^{\circ}$ out of phase with the Skerries, i.e. within about an hour of being $180^{\circ}$ out-of-phase. It may therefore be useful for future energy development to exploit a wider range of current speeds, increasing the phase diversity between sites, and therefore providing more opportunities for firm power generation by tidal currents. For

\footnotetext{
${ }^{1}$ For the M2 tidal constituent, $360^{\circ}$ represents $12.42 \mathrm{~h}$.
} 
(a) Tidal power for individual sites

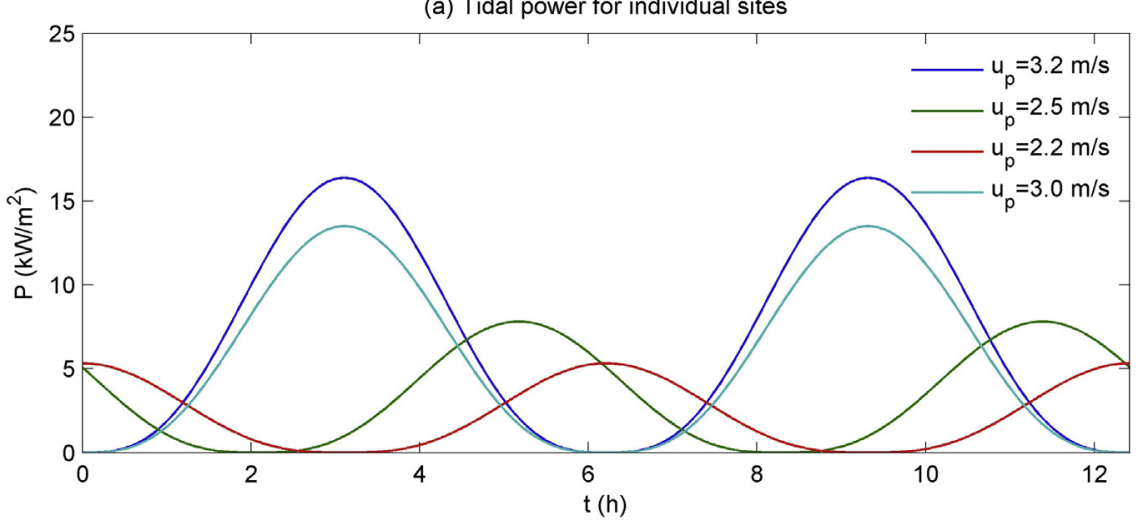

(b) Normalised combined tidal power of two sites

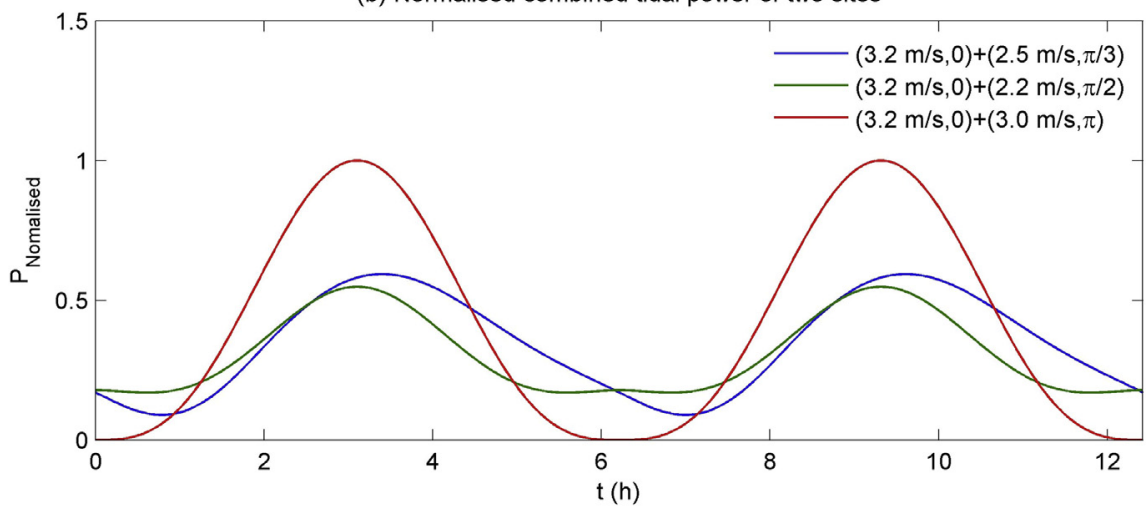

(c) Sensitivity of the objective function to $\lambda$

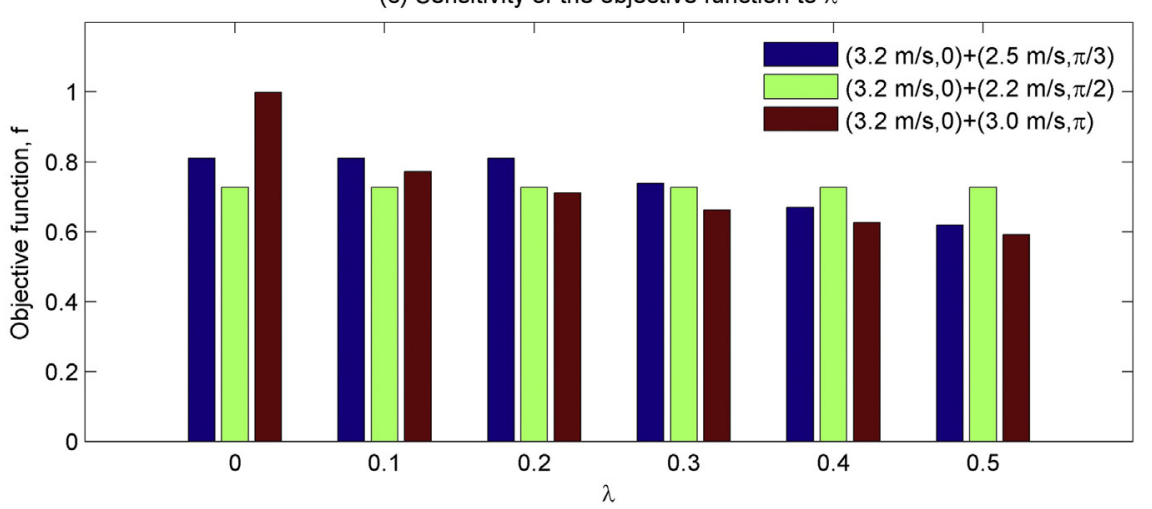

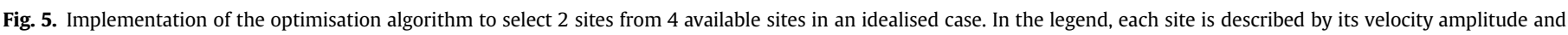
phase, $\left(u_{p}, g\right)$.

example, a plot of the relationship between the phase and amplitude of the tidal currents over the NW European shelf seas (Fig. 6) shows that the highest tidal stream sites are around $180^{\circ}$ out-of-phase with one another, but there is less distinction in phase when we consider lower tidal amplitudes. For example, for a threshold M2 current amplitude of $2 \mathrm{~m} / \mathrm{s}$, peak generation occurs somewhere over the shelf (in many instances at multiple locations) for around $40 \%$ of the time, whereas for a threshold current amplitude of $1.0 \mathrm{~m} / \mathrm{s}$, peak generation occurs at multiple locations for $>90 \%$ of the time. For this reason, we consider a range of thresholds for M2 current amplitude in our application of the greedy algorithm $(1.5-2.5 \mathrm{~m} / \mathrm{s})$.

We assume that future tidal stream sites will be developed in arrays, rather than as geographically discrete individual devices, and we assume that each array will comprise 10 devices. In all simulations, we make the assumption that the first array will be placed in the Pentland Firth. Although this may not necessarily be the case in practice (for example, the Anglesey Skerries site could become the first array in the world), the Pentland Firth contains the highest density of resource over the NW European shelf seas, and will therefore be developed early in any marine energy roadmap. In addition, we did not find the algorithm to be sensitive to initial site selection. We consider scenarios of 20, 50, 100, 200, 500 and 1000 arrays optimally placed by the greedy algorithm for the two threshold M2 current amplitudes. We do not assign particular timescales to such development, but is likely that the 20 array scenario could be achieved within the next decade, and the 1000 array scenario possible by the end of this century. 
(a) all water depths

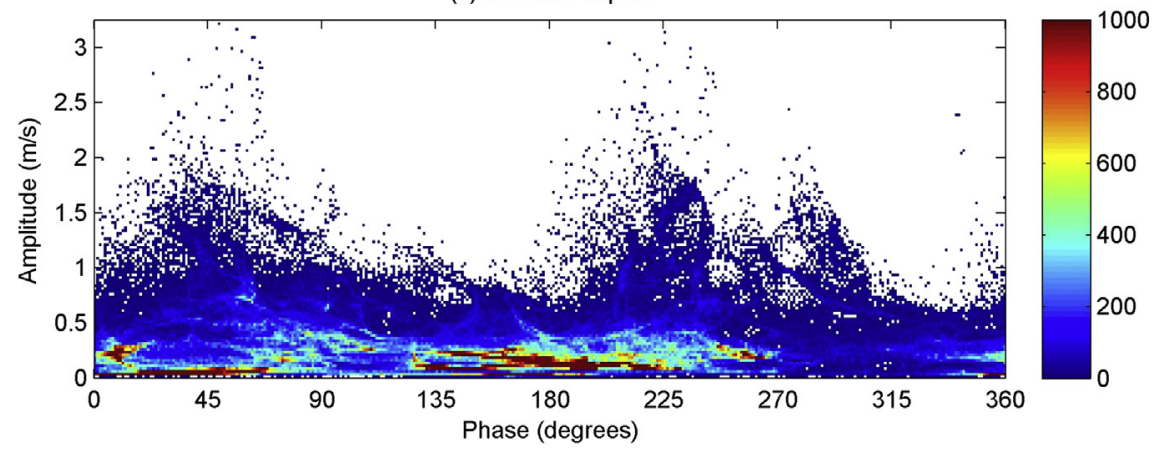

(b) $25<\mathrm{h}<50 \mathrm{~m}$

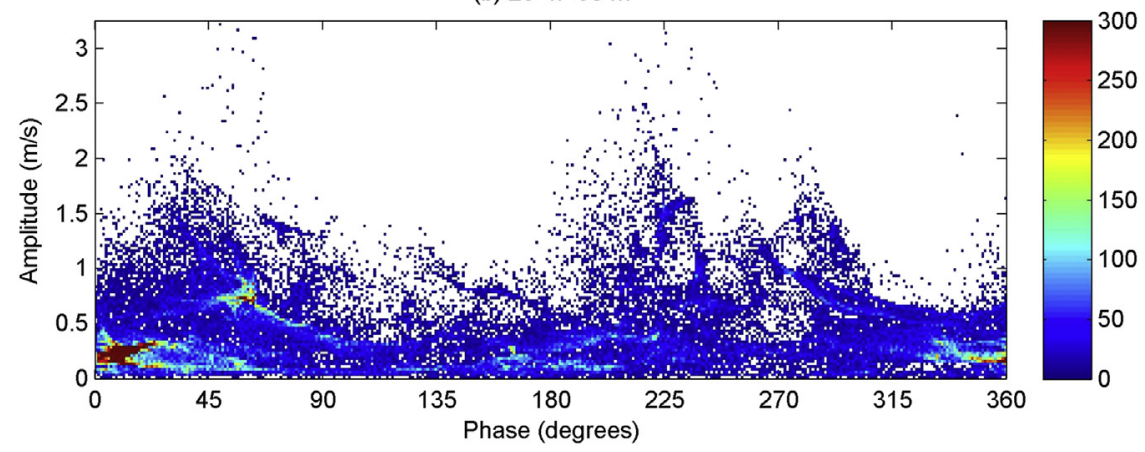

Fig. 6. Relationship between phase and amplitude of the M2 tidal currents over the NW European shelf seas for (a) all water depths, and (b) water depths in the range $25<h<50 \mathrm{~m}$. Colour scale is area in $\mathrm{km}^{2}$.

\section{Results}

We consider first the case where the minimum M2 current amplitude is $2.0 \mathrm{~m} / \mathrm{s}$ (Fig. 7). Along with the Pentland Firth, the
Channel Islands (distinguished here as 'Normandy' and 'Brittany') are key sites for development at low numbers of arrays (up to 20), with further development at the Anglesey Skerries and the Faroe Islands at 50 arrays (Fig. 8). Subsequent sites for development at the
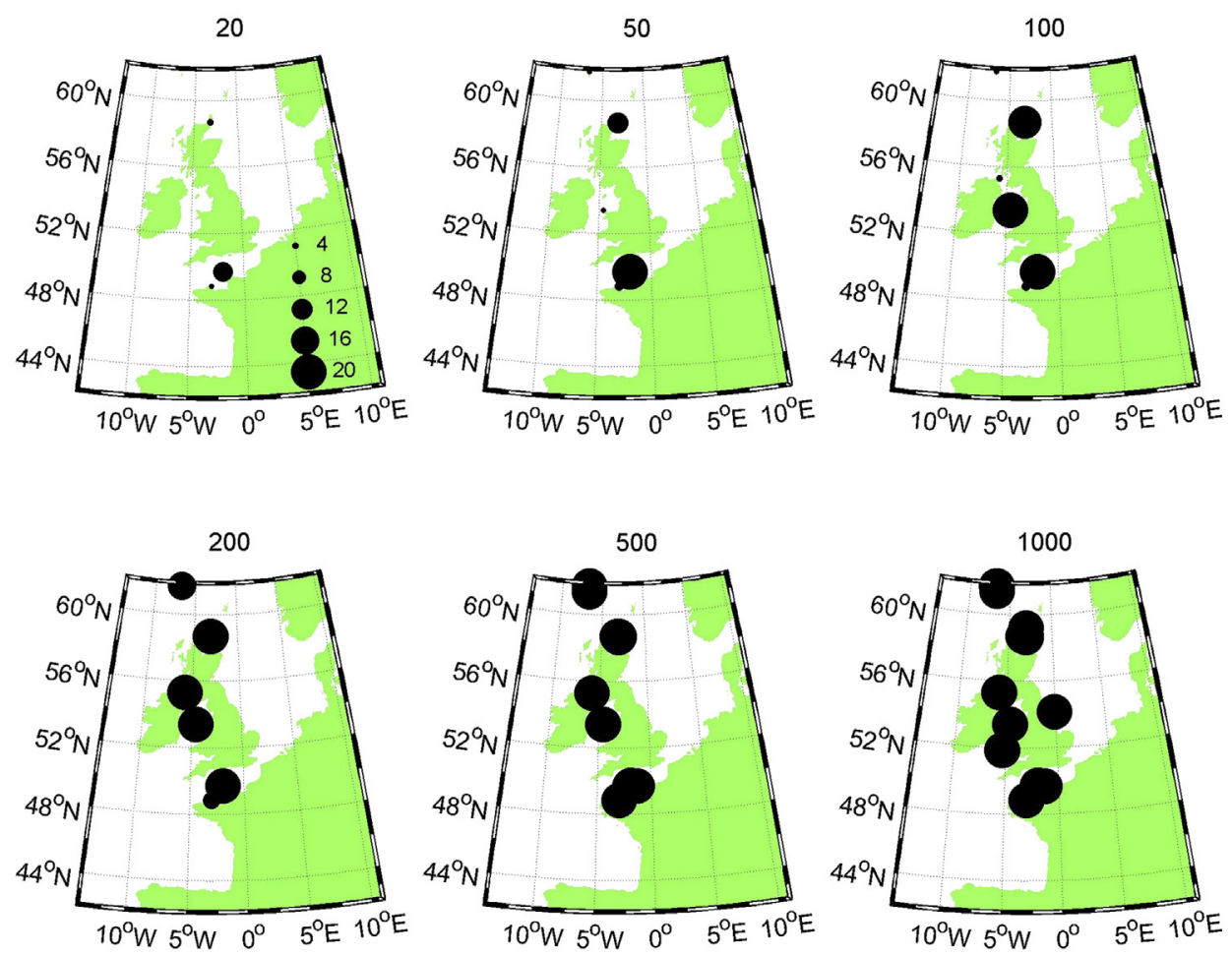

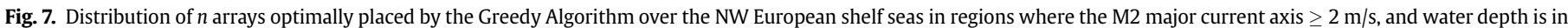

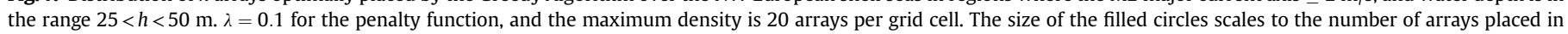
each grid cell, and a legend is provided in the top left panel. 


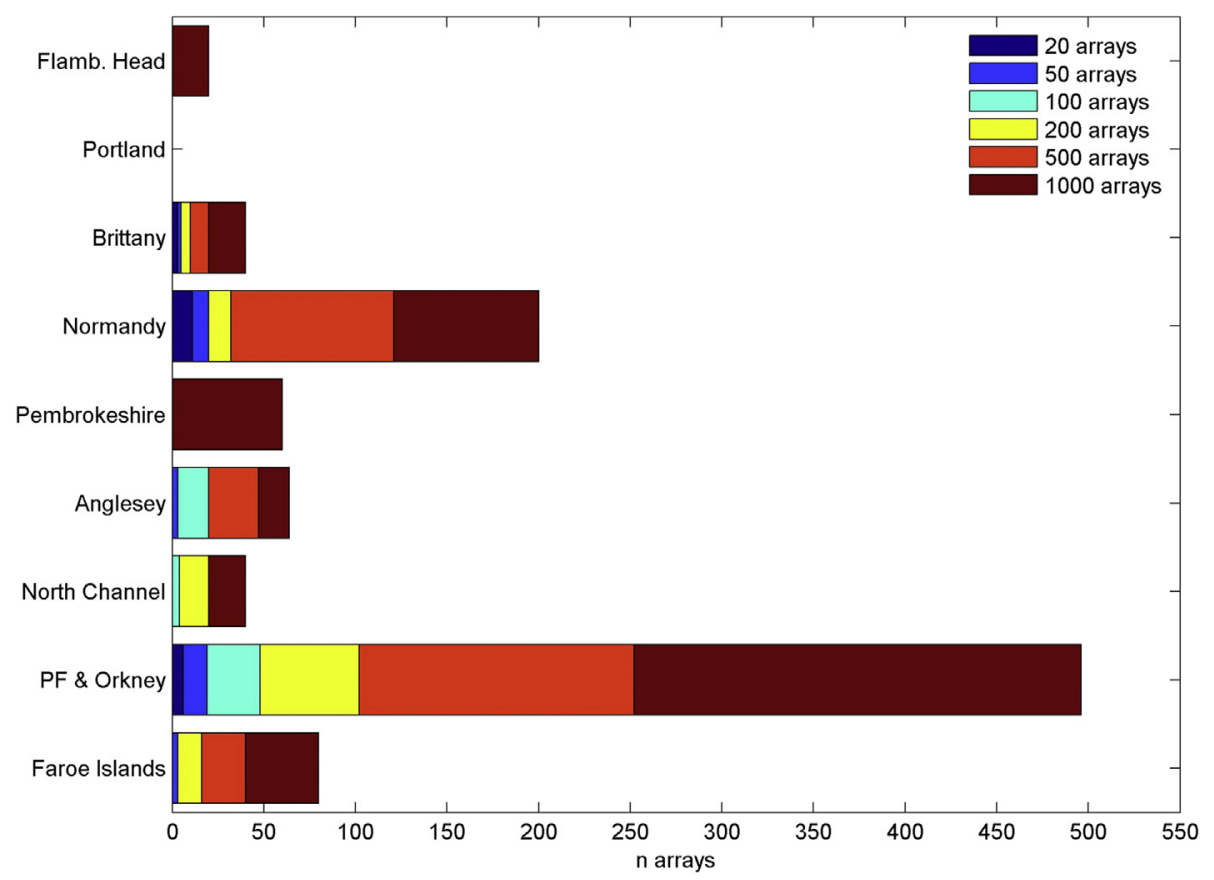

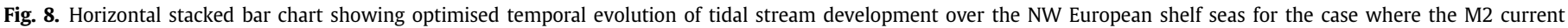
amplitude is $\geq 2 \mathrm{~m} / \mathrm{s}$. Each array is assumed to comprise of 10 devices, with an array capacity of around $20 \mathrm{MW}$.

100 array scale include the North Channel, joined by Pembrokeshire and Flamborough Head at 1000 arrays - there is also considerable consolidation in the Pentland Firth and Normany at this scale. When the minimum M2 current amplitude was reduced to $1.5 \mathrm{~m} / \mathrm{s}$, the optimal distribution was identical to the $2.0 \mathrm{~m} / \mathrm{s}$ case, indicating that there is sufficient sea space to accommodate the array numbers simulated here and, since power is a function of velocity cubed (Eq. (1)), optimisation is generally dominated by amplitude rather than phase. Sensitivity to a wider range of velocity thresholds is provided in the next section.

\subsection{Sensitivity}

As mentioned in the previous section, the results are not affected by changing the threshold for M2 current amplitude in the range $1.5-2.0 \mathrm{~m} / \mathrm{s}$. Here, we extend this sensitivity to include thresholds in the range $1.5-2.5 \mathrm{~m} / \mathrm{s}$. We provide the results of this sensitivity test only at the 1000 array scale (Fig. 9). This figure demonstrates clearly that there is no difference in the optimal distribution when the M2 current amplitude is in the range $1.5-2.0 \mathrm{~m} / \mathrm{s}$, but that there are a few differences when the

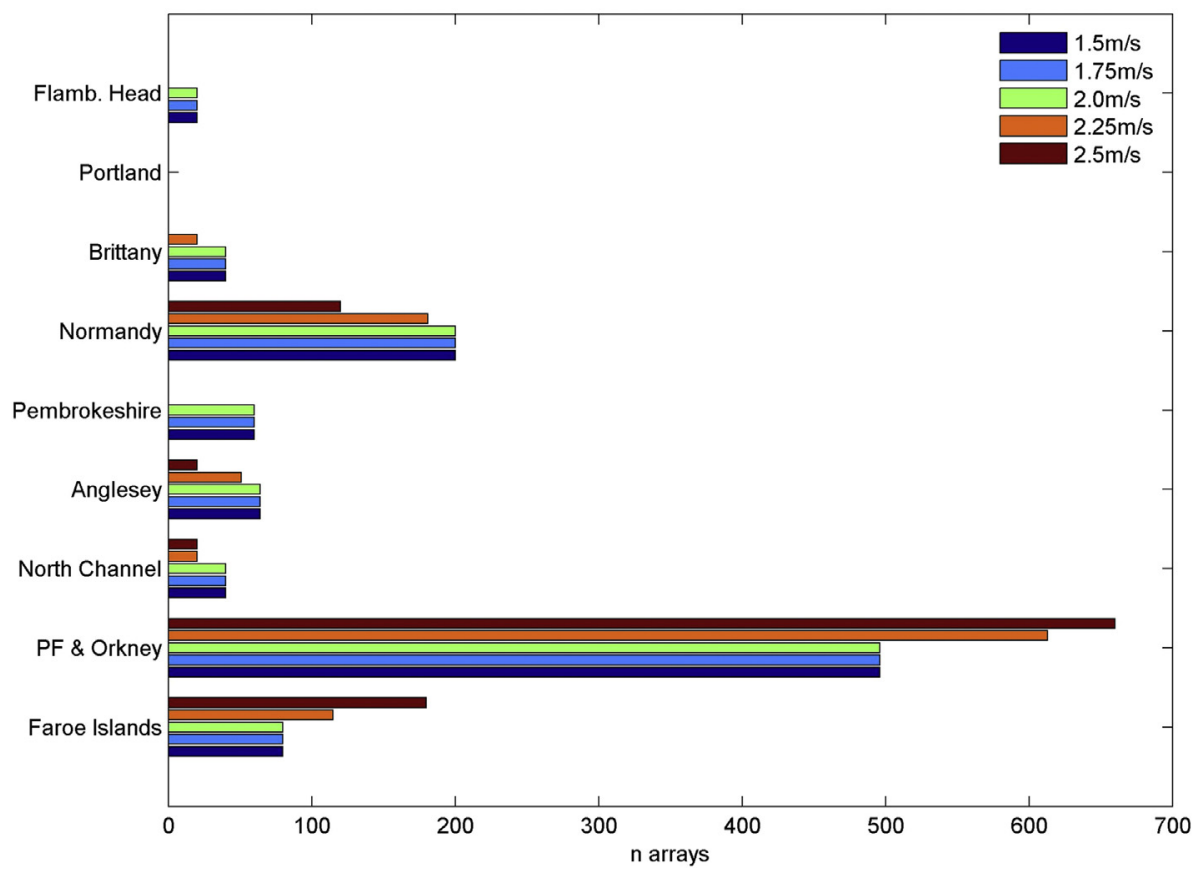

Fig. 9. Sensitivity of greedy algorithm to threshold M2 current amplitude values in the range $1.5-2.5 \mathrm{~m} / \mathrm{s}$. These results are for $n=1000$ arrays. 
threshold is increased to $2.25-2.5 \mathrm{~m} / \mathrm{s}$. Of most significance, increasing the threshold favours the development of the Pentland Firth and the Faroe Islands, at the expense of the Channel Islands, and regions such as the Irish Sea and North Sea. However, in general, the overall distribution is broadly similar when the M2 current amplitude is varied over the range $1.5-2.5 \mathrm{~m} / \mathrm{s}$.

We also examined the sensitivity of the results to the value of $\lambda$ in the penalty function (Eq. (3)). We apply this sensitivity analysis only to the case where the M2 current amplitude is $\geq 2.0 \mathrm{~m} / \mathrm{s}$ (Fig. 10). Although there are differences between all of the sensitivity cases, the largest differences occur when $\lambda \geq 0.2$, i.e. where there is a significant penalty when instantaneous power generation reduces below $20-30 \%$ of the mean. Since these scenarios are rather prohibitive, these cases indicate the policy that would evolve if phase were not an important variable in site selection, and if only the amplitude of currents were considered - a situation that is not dissimilar to the current state of the marine renewable energy industry. In such a case, there is a major shift in emphasis from the Pentland Firth to Normandy, with a relatively even resource exploitation distributed between Anglesey, the North Channel, Pentland Firth and the Faroe Islands. However, we note that there is relatively little sensitivity in the long-term optimal distribution for more modest values of $\lambda$, e.g. in the range $0.05<\lambda<0.10$, particularly for cases up to 500 arrays.

\section{Discussion}

Up to the scale of 100 arrays, the optimal distribution of tidal stream sites over the NW European shelf seas was identical for the cases where the threshold M2 current amplitude was in the range $1.0-2.0 \mathrm{~m} / \mathrm{s}$, with development concentrated on the Pentland Firth, the Channel Islands ('Normandy' and 'Brittany'), and Anglesey. For larger exploitation (e.g. up to 1000 arrays), there is a higher concentration in the Irish Sea and Faroe Islands, with some development at Flamborough Head in the North Sea.

In agreement with Iyer et al. [7], and extending the analysis to the entire NW European shelf seas, there is minimal phase diversity across the high energy European tidal stream sites to deliver firm power generation. This is primarily because the resource is concentrated at a relatively low number of sites, e.g. the nine sites identified in Fig. 10. However, if we consider the vertical tides (through, for example, the development of lagoons and impoundments), we see that through careful consideration and site selection, vertical and horizontal tides could together provide a more continuous source of electricity generation (Fig. 11). There are many strategies to generate electricity from the vertical tide, and such discussion is beyond the remit of this study, but clearly there is some scope for exploiting the phase relationship between the high tidal range and strong tidal stream sites.

This is a relatively preliminary study, and there are many ways in which such work could be improved. One way is to improve the hydrodynamic model by increasing the horizontal resolution, and by using more tidal constituents in the greedy algorithm. With respect to the latter, the phase relationship between multiple constituents such as M2 and S2 could be explored to see how best the resource could be optimised over, for example, a spring-neap cycle. In addition, considerable complexity could be introduced into the optimisation algorithm, such as including additional penalty functions to weight variables such as distance to shore, proximity to grid connection, and distance to regions of high energy demand. However, quantifying some of these weightings objectively could be difficult, and would require detailed information on local and national grid characteristics. Finally, we did not include feedback between energy extraction and the resource in our calculations. This would be very difficult to achieve, since at each step of the greedy algorithm, many thousands of scenarios are tested (a) $\lambda=0.05$

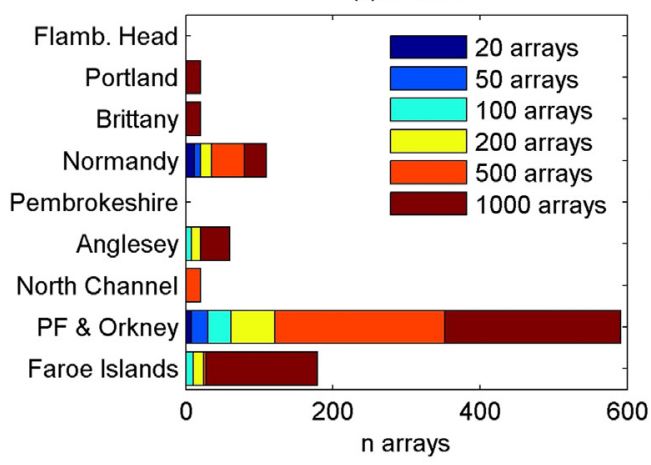

(c) $\lambda=0.20$

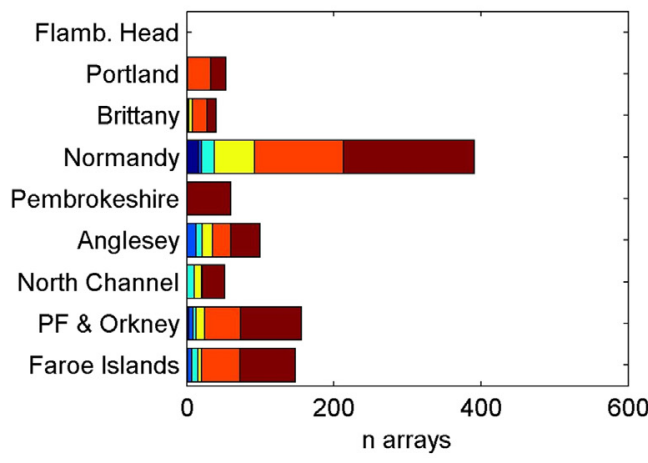

(b) $\lambda=0.10$

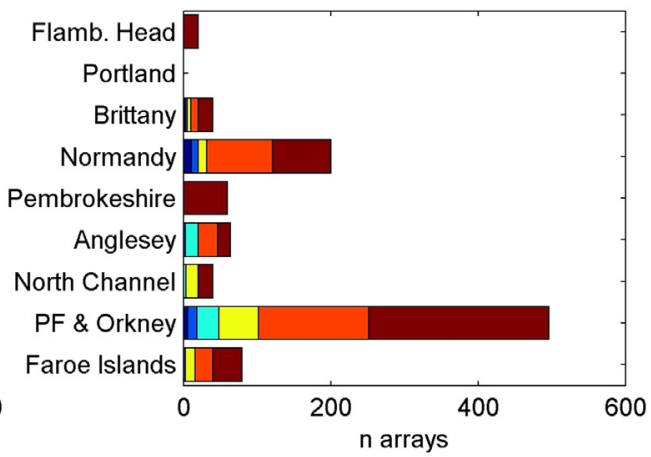

(d) $\lambda=0.30$

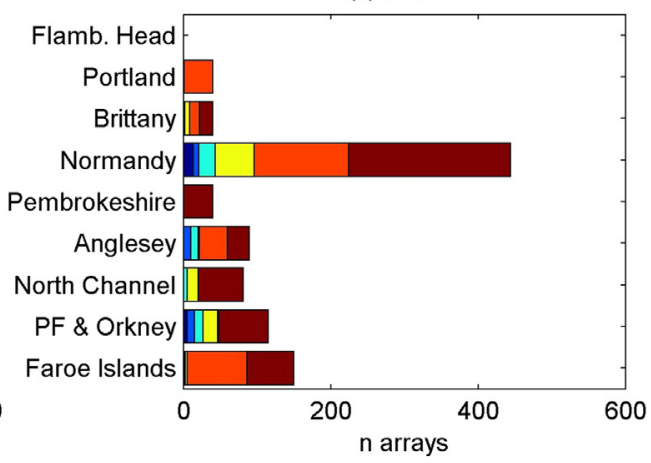

Fig. 10. Sensitivity of greedy algorithm optimisation to the value of $\lambda$ for cases where the minimum M2 current amplitude is $2.0 \mathrm{~m} / \mathrm{s}$. 
(a) Horizontal tide

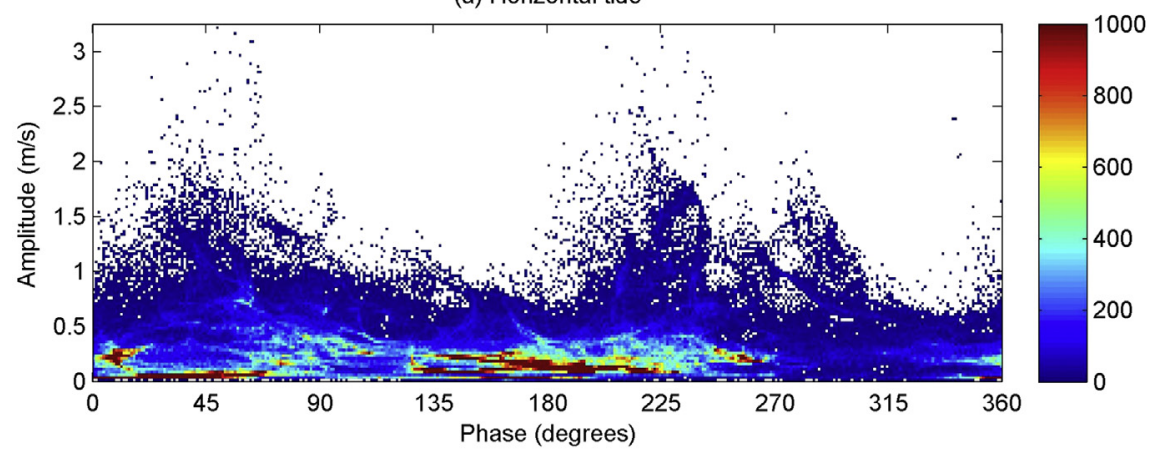

(b) Vertical tide

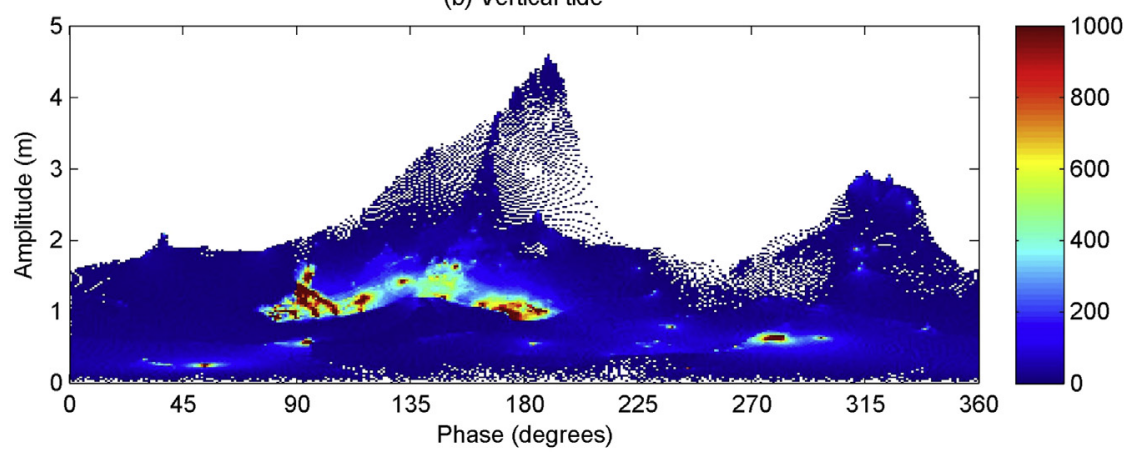

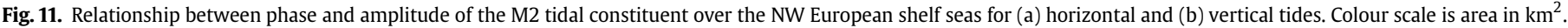

before selecting the next optimal site for development. The hydrodynamic model cannot possibly be run with additional energy extraction terms for each of these cases. Rather, such feedbacks would have to be parameterised as a post-process in the hydrodynamic model outputs, using methods similar to the parameterisation of wake effects in wind array optimisation problems, [e.g. Ref. [27]]. Accounting for feedbacks between energy extraction and the resource is clear scope for further work with large-scale optimisation problems.

\section{Conclusions}

This study has provided recommendations on how best to optimise the European tidal stream resource over a range of future scenarios. We generally find that over the next several decades, the favourable phasing between the Pentland Firth, the Channel Islands and Anglesey makes these the most strategic tidal stream sites to develop in order to maximise mean power and minimise periods of low power generation. At larger scales of exploitation, our optimisation indicates that such developments should be complemented by sites in the Irish Sea and Faroe Islands. However, regardless of the numerous ways in which the European tidal stream resource can be optimised, it cannot on its own provide firm power generation, and so it is important to consider the parallel investment in schemes which generate electricity from the vertical tides.

\section{Acknowledgements}

We thank the editor of Energy and two anonymous reviewers for their comments on an earlier draft of the manuscript. MRH acknowledges the support of the SEACAMS project, which is partfunded by the European Union's Convergence European Regional Development Fund, administered by the Welsh Government (Grant number: 80284). SPN and MJL acknowledge the support of EPSRC SuperGen project EP/J010200/1.

\section{References}

[1] Neill SP, Hashemi MR. Wave power variability over the northwest European shelf seas. Appl Energy 2013;106:31-46.

[2] Pugh DT. Tides, surges and mean sea-level (reprinted with corrections). John Wiley \& Sons Ltd; 1996.

[3] Myers L, Bahaj AS. Simulated electrical power potential harnessed by marine current turbine arrays in the Alderney Race. Renew Energy 2005;30: $1713-31$.

[4] Bahaj AS. Generating electricity from the oceans. Renew Sustain Energy Rev 2011;15:3399-416.

[5] Ben Elghali SE, Benbouzid MEH, Charpentier JF. Marine tidal current electric power generation technology: state of the art and current status. In: Electric Machines \& Drives Conference, 2007. IEMDC'07. IEEE International; vol. 2. IEEE; 2007, p. 1407-12.

[6] Rourke FO, Boyle F, Reynolds A. Marine current energy devices: current status and possible future applications in Ireland. Renew Sustain Energy Rev 2010; $14: 1026-36$.

[7] Iyer AS, Couch SJ, Harrison GP, Wallace AR. Variability and phasing of tidal current energy around the United Kingdom. Renew Energy 2013;51:343-57.

[8] MaCilwain C. Supergrid Nat 2010;468:624-5.

[9] Mueller M, Wallace R. Enabling science and technology for marine renewable energy. Energy Policy 2008;36:4376-82.

[10] Song MX, Chen K, He ZY, Zhang X. Optimization of wind farm micro-siting for complex terrain using greedy algorithm. Energy 2014;67:454-9.

[11] Woolf DK, Easton MC, Bowyer PA, Mcllvenny J. The physics and hydrodynamic setting of marine renewable energy. In: Marine renewable energy technology and environmental interactions. Springer; 2014. pp. 5-20.

[12] Huntley DA. Tides on the north-west European continental shelf. In: Banner FT, Collins MB, Massie KS, editors. The north-west European shelf seas: the sea bed and the sea in motion. II. Physical and chemical oceanography, and physical resources. Elsevier; 1980. pp. 301-51.

[13] Kwong SCM, Davies AM, Flather RA. A three-dimensional model of the principal tides on the European shelf. Prog Oceanogr 1997;39:205-62.

[14] Holt JT, James ID, Jones JE. An s coordinate density evolving model of the northwest European continental shelf: 2 seasonal currents and tides. J Geophys Res 2001;106:14035-53.

[15] Howarth MJ. Tidal currents of the continental shelf. In: Stride A, editor: Offshore tidal sands, processes and deposits. London: Chapman Hall; 1982. pp. 10-26. 
[16] Davies A, Kwong S. Tidal energy fluxes and dissipation on the European continental shelf. J Geophys Res 2000;105:21969-89.

[17] Adcock TAA, Draper S, Houlsby GT, Borthwick AGL, Serhadlıoğlu S. The available power from tidal stream turbines in the Pentland Firth. Proc Roy Soc A Math Phys Eng Sci 2013;469:2157.

[18] Neill SP, Jordan JR, Couch SJ. Impact of tidal energy converter (TEC) arrays on the dynamics of headland sand banks. Renew Energy 2012;37:387-97.

[19] Blunden LS, Bahaj AS. Initial evaluation of tidal stream energy resources at Portland Bill, UK. Renew Energy 2006:31:121-32.

[20] Serhadlıoglu S, Adcock TAA, Houlsby GT, Draper S, Borthwick AGL. Tidal stream energy resource assessment of the Anglesey Skerries. Int J Mar Energy 2013;3:e98-111.

[21] Shchepetkin AF, McWilliams JC. The regional oceanic modeling system (ROMS): a split-explicit, free-surface, topography-following-coordinate oceanic model. Ocean Model 2005;9:347-404.
[22] Warner JC, Sherwood CR, Signell RP, Harris CK, Arango HG. Development of a three-dimensional, regional, coupled wave, current, and sediment-transport model. Comput Geosci 2008;34:1284-306.

[23] Chassignet EP, Arango H, Dietrich D, Ezer T, Ghil M, Haidvogel DB, et al DAMEE-NAB: the base experiments. Dyn Atmos Oceans 2000;32:155-83.

[24] Neill SP, Hashemi MR, Lewis MJ. The role of tidal asymmetry in characterizing the tidal energy resource of Orkney. Renew Energy 2014;68:337-50.

[25] Hashemi MR, Neill SP. The role of tides in shelf-scale simulations of the wave energy resource. Renew Energy 2014:69:300-10.

[26] Boginski V, Butenko S, Pardalos PM. Statistical analysis of financial networks. Comput Stat Data Anal 2005;48:431-43.

[27] Pookpunt S, Ongsakul W. Optimal placement of wind turbines within wind farm using binary particle swarm optimization with time-varying acceleration coefficients. Renew Energy 2013;55:266-76. 